\title{
Effect of Brain-Stem Lesions on Conditioned Responses of Cats
}

\author{
Robert W. Doty, EDWard C. Beck, and KenNeth A. KoOI ${ }^{1}$ \\ Department of Physiology, University of Michigan, Ann Arbor, Michigan, and \\ Clinical Psychology and Neurology Services, Veterans Administration Hospital, \\ Fort Douglas Division, Salt Lake City, Utah \\ Received May 11, 1959
}

\begin{abstract}
The possibility was explored that certain central brain-stem areas might be critical for the performance of conditioned reflexes. In 6 cats, large bilateral electrolytic lesions were placed in the medial diencephalon or mesencephalon and subsequently defined by histology. A tone served as conditional stimulus and footshock as unconditional stimulus. The EEG, respiration, and the EMG of the conditioned limb were recorded. Persistent low voltage, fast activity consistently reappeared in the EEG in 7 to 10 days and was seen even after destruction of over $100 \mathrm{~mm}^{3}$ of the mesencephalon, including the reticular formation. Conditioned reflexes usually appeared only when such faster EEG patterns were present. Conditioned reflexes and discrimination between tones could occur, however, during relatively high voltage, slow activity in the cortical areas sampled. Extensive lesions essentially transecting the ascending reticular system or destroying the posterior hypothalamus did not preclude conditioning. In contrast, one animal could not be retrained when lesions were in the mamillary area. It is concluded that the medial mesencephalic systems are not essential for this type of conditioning and that, if any essential system does exist, it is located in the region of the mamillary bodies, field $\mathrm{H}_{1}$ of Forel, center median, and the habenulopeduncular tract.
\end{abstract}

\section{Introduction}

Preceding experiments have demonstrated in cats under moderate bulbocapnine sedation that EEG arousal reactions to a conditional stimulus are acquired and become highly consistent prior to the appearance of any respiratory or flexion conditioned reflexes, and invariably accompany these

1 Supported by a research grant (B-938) from the National Institute of Neurological Diseases and Blindness of the National Institutes of Health, Public Health Service. The authors wish to thank Mr. R. F. Cooper for his skillful preparation of the histologic material and his participation in training some of the animals. The present address of Dr. Kooi is: Laboratory of Electroenccphalography, Department of Psychiatry, University of Michigan, Ann Arbor, Michigan. 
somatic conditioned reflexes in the earlier stages of training (4). This suggests, as does common experience, that the state of alertness and the neural systems regulating it are essential components of the conditioning process. The brain-stem reticular or "centrencephalic" (18) systems, by reason of the convergence of afferent stimuli from multiple sensory modalities $(1,22)$ and as a consequence of their extensive and commanding corticipetal influences, are well qualified for such an integrative role. The reticular system has already been implicated in the reported alteration of potentials evoked by behaviorally significant stimuli $(7,10)$. Gastaut and his colleagues (8), Yoshii, Pruvot, Gastaut (25), and Lissak (17) have also assigned cardinal importance to subcortical events in the evolution of conditioned responses.

The experiments reported below were undertaken to gain some direct evaluation of the learning capabilities of cats following severe bilateral destruction of major portions of these brain-stem regions. Such endeavor is fraught with difficulties of both technical and theoretical nature. However, there is some reason to hope, especially as they confirm earlier impressions (3), that these experiments can serve as guideposts for future effort. They indicate that despite the highly debilitating consequences of its destruction, the mesencephalic reticular formation is largely dispensable to the conditioning process, whereas the central thalamic and posterior hypothalamic nuclei are more likely to be the site of some mechanism critical for conditioning or learning.

\section{Method}

As previously described (4), the animals were conditioned to a 2 -sec. tonal conditional stimulus and unavoidable shock as unconditional stimulus applied to a hind leg thirty to fifty times per day. The EEG was taken from implanted electrodes.

Electrolytic lesions were placed stereotaxically in the usual manner. Thorough postoperative care of the animals was essential. Solutions of 5 per cent dextrose, B vitamins, and 0.9 per cent $\mathrm{NaCl}$ were given subcutaneously, about $100 \mathrm{ml}$ each per day, in the immediate postoperative period. Gavage feeding of milk and the force-feeding of chunks of raw kidney and liver were then begun. Antibiotic therapy was continued for most of the survival period. Temperature regulation was, of course, extremely disturbed, but this never appeared to be a cause of death, save in one animal which, in the initial cataleptic state, was overheated in the 
effort to keep body temperature near normal. Following this experience, heating devices were used sparingly and most reliance was placed on keeping the animals "embedded" in crumpled newspapers in a small box.

At the termination of experiments, the animals were anesthetized with Nembutal and the cortex completely exposed under a protective pool of warm mineral oil. Potentials evoked by photic and auditory stimuli, or electrical stimulation of the sciatic nerve of the conditioned limb were recorded between silver ball electrodes on the pia mater and a reference screw in the lambdoidal ridge.

The brains were perfused with saline followed by 10 per cent formalin, embedded in celloidin, cut in $50-\mu$ sections, and stained with Weil, Nissl, and Klüver techniques. The volume of the lesions was estimated by projecting every fourth histologic section onto paper, cutting out an area of paper corresponding to the destroyed area, and weighing the total paper so obtained. A correction factor of 25 per cent was added to each cstimate to allow for shrinkage observed during celloidin imbedding. The lesion volume for one brain was determined a second time 9 months after the first estimate had been made. The two estimates differed by only 0.15 per cent.

\section{Results}

Since each animal is unique, a summary of the protocols is presented for the seven most informative experiments. The general behavior of the animals differed little from that already described in detail by others $(12$, $13,16)$.

\section{Lesions Centered on Mesencephalic Areas}

Cat 11. About $100 \mathrm{~mm}^{3}$ of the central brain stem was destroyed including all of the red nucleus (Fig. 1). Mamillary bodies were intact as were anterior and lateral portions of the center median. Intact fibers could be seen in the mesencephalic reticular formation on the left side (Fig. 1), though cell loss there appeared to be considerable. The posterior $2 \mathrm{~mm}$ of the corpus callosum and fornix was severed. ${ }^{2}$

The animal was kept for 80 days during which time it progressed from complete stupor during the first postoperative days to spontaneous walking and eating. Rectal temperature was $29.5^{\circ} \mathrm{C}$ on the first postoperative day, $34^{\circ} \mathrm{C}$ the following day, and from then on improved to nearly normal.

2 Photomicrographs of this brain can be seen in Fig. 148, Ref. 6. 


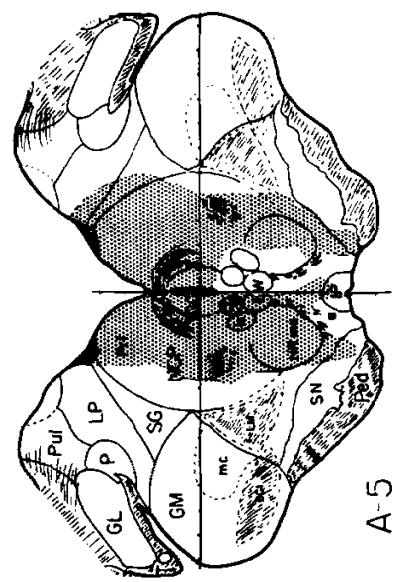

它

荡

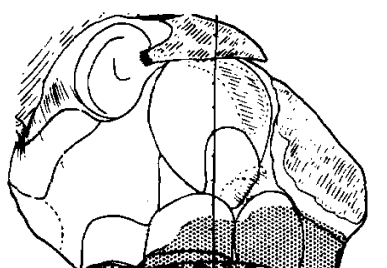

㤩昆

胥 -1

㟧

女
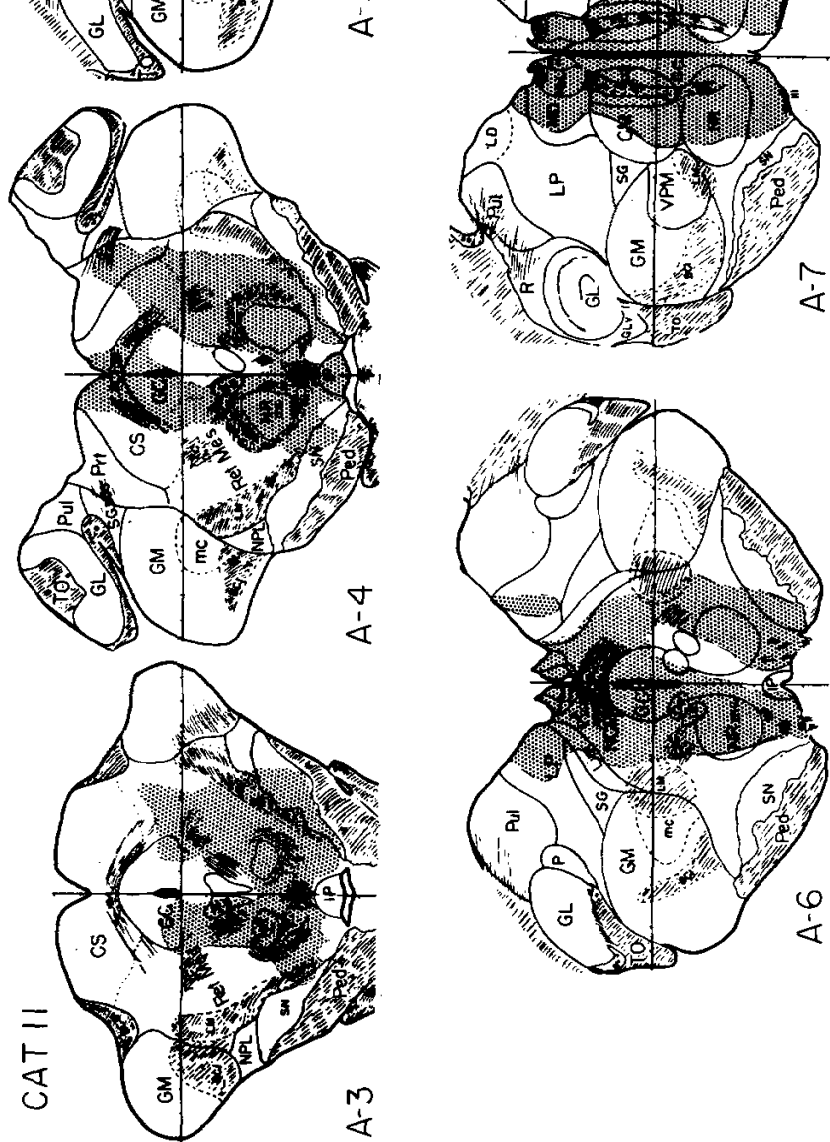

능

蛋

.

옹

:

宽

n

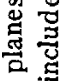

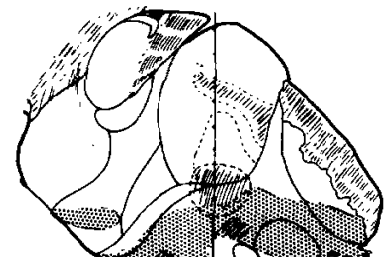

茫

ज

总

离

案

$\stackrel{8}{8}$

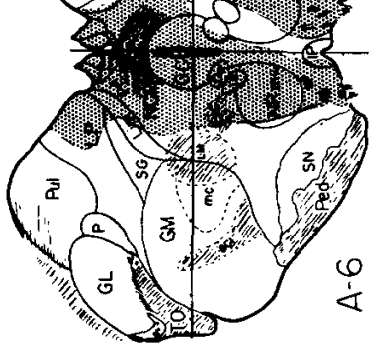

范

要

40

व

合

ज豞

- 뽕

量 
After 2 weeks of recovery, akinesis was still the predominant state, but it was possible to arouse directed attack behavior during force-feeding. After 3 weeks, the cat could sit for a few seconds, scratch its head with the hind leg, make efforts to walk, and eat when food was placed in its mouth. During the eighth and ninth weeks it began to walk and eat alone. It would attack another cat placed nearby, and showed a rage reaction that was conditioned to the stimulus of rubbing the hind leg with alcohol prior to antibiotic injection. However, if the experimenter held out his hand slowly, the animal extended its chin to be rubbed. Cataleptic posturing and extensor rigidity were still prominent features. Visual tracking of a moving object was poor, but present. The eyes blinked to sudden approach of an object.

To determine whether conditioned reflexes could be established subsequent to mesencephalic lesions, this animal had been given no preoperative training. Pairing of conditional and unconditional stimuli was thus begun 1 week after surgery. The EEG at this time was still dominated by high voltage, slow activity (Fig. 2). Arousal to low voltage, fast patterns rarely persisted beyond $2 \mathrm{sec}$ even following presentation of a 45 -volt DC shock (as unconditional stimulus) to the moistened skin between the toes. Click stimuli evoked spike potentials in middle ectosylvian gyrus, but no auditory stimulus would produce a low voltage, fast EEG response. The heart rate was about 150 per minute and decreased to 135 per minute following the unconditional stimulus. Respiration was 36 per minute but increased to nearly 60 per minute when the unconditional stimulus was given frequently. Ten presentations of conditional stimulus alone showed no reaction, but after ten pairings of conditional and unconditional stimuli, a stiffening of the conditioned limb to the conditional stimulus was observed visually and was recorded as a diminution in the flexor EMG (Fig. 2a). This response remained fairly consistent for the remainder of this training session (total of 50 trials), but could be elicited by nonspecific stimuli such as a hand clap or shouting. After this session this response was never seen again. At the twenty-eighth presentation, an alteration in respiration occurred to the conditional stimulus, but this occurred only once more this day (Fig. 2c). No alteration in EEG pattern to the conditional stimulus was observed (Fig. 2).

The respiratory conditioned reflexes remained infrequent and equivocal for the next few days of training. Respiratory conditioned reflexes became more definite as low voltage, fast patterns returned in the EEG. By the 
thirteenth postoperative day when long runs of low voltage, fast activity began to be recorded consistently, the respiratory conditioned reflexes occurred to almost every presentation of the conditional stimulus. The animal had received a total of 170 pairings prior to this. As a general rule, no respiratory conditioned reflex occurred unless low voltage, fast patterns
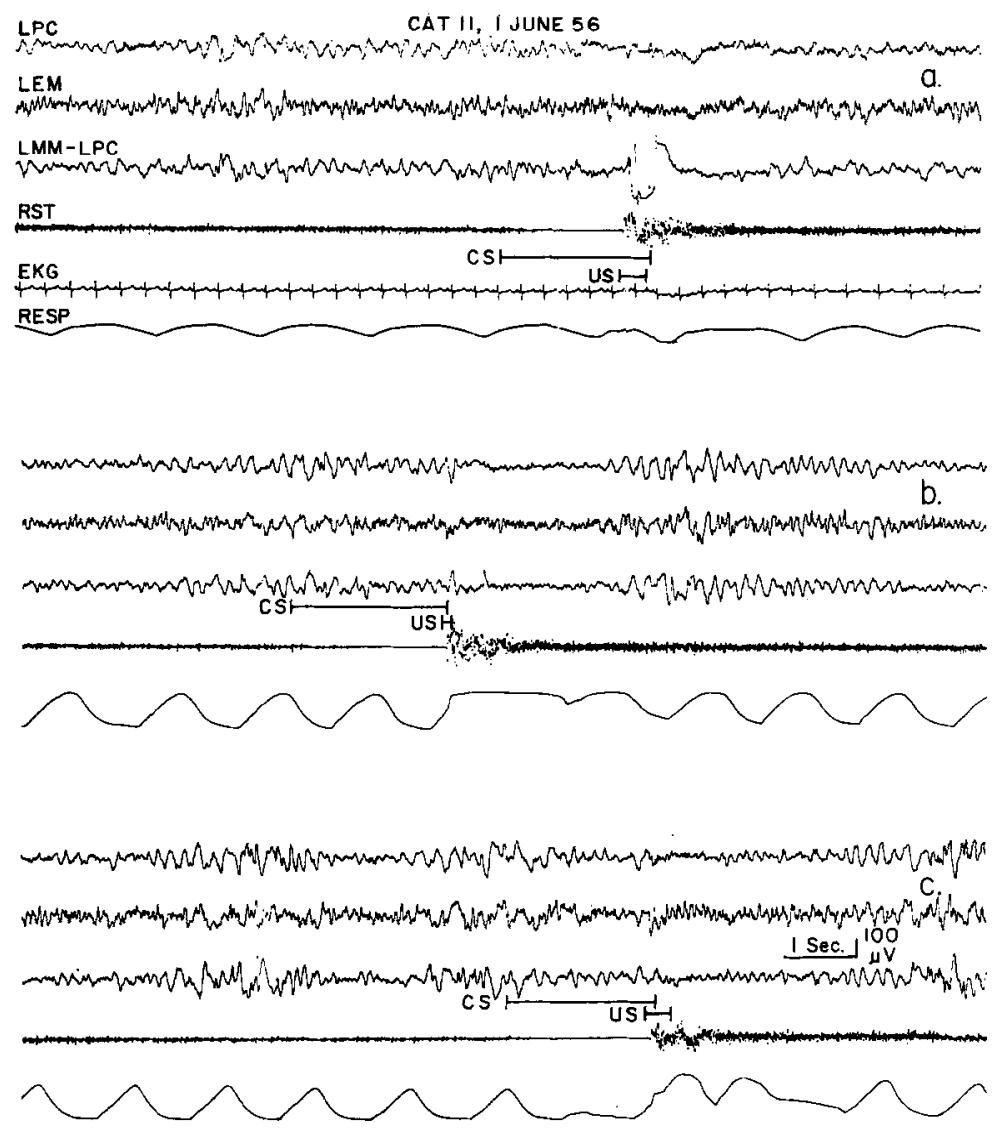

FIG. 2. Cat 11, first recording and training session 1 week following lesion placement: a, eleventh pairing of conditional and unconditional stimuli; $b$, twenty-firsț; c, forty-fifth. Note decreased EMG which corresponded to a stiffening of the leg, and the respiratory change to the conditional stimulus. Abbreviations in this and other figures: $\mathbf{R}$ and $\mathrm{L}$, right and left; $\mathrm{PC}$, post cruciate gyrus; EM, middle ectosylvian gyrus; MM, middle portion of marginal gyrus; ST, EMG of semitendinosus muscle; RESP, respiration. 
were present (Fig. 3a, c) but there were occasional exceptions (Figs. 3b and $2 \mathrm{c}$ ).
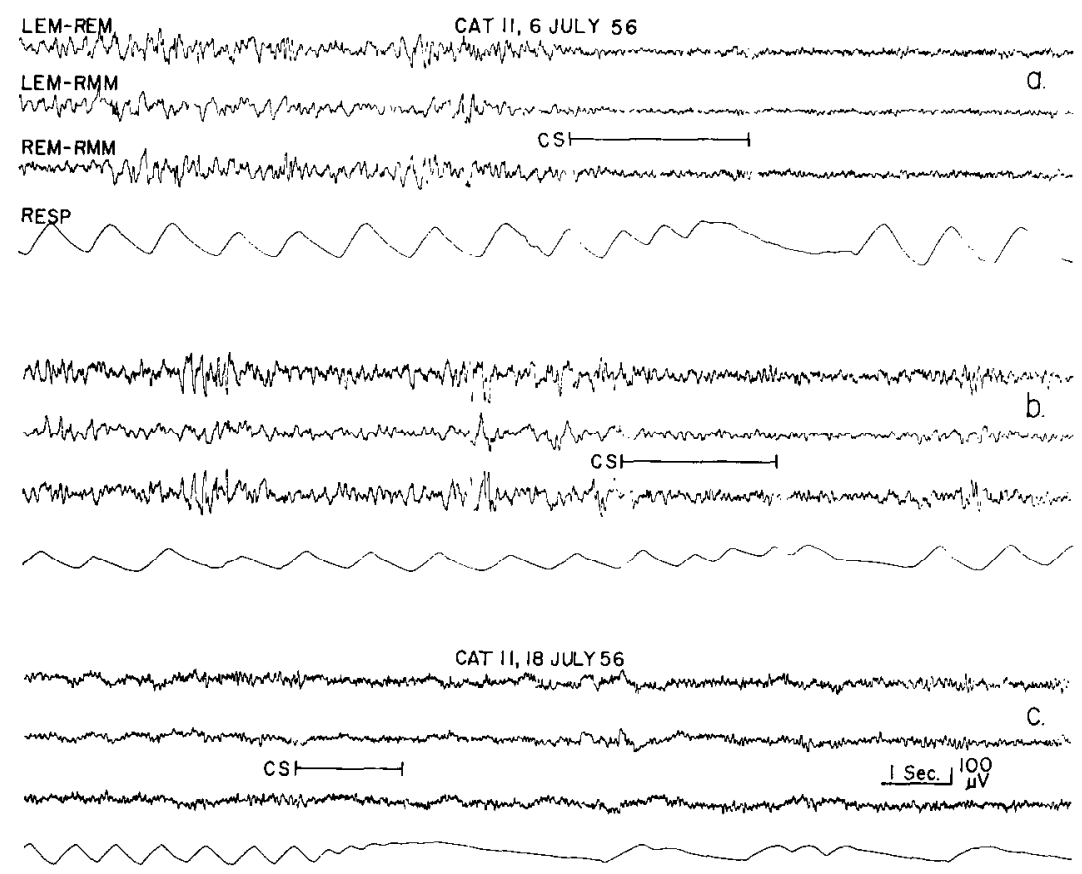

FIG. 3. Records from cat 11 on the forty-fourth (a and b) and fifty-sixth (c) postoperative days showing respiratory conditioned reflexes with and without concomitant EEG arousal reactions. Record a is the fifth presentation of the 700 cycles per second tonal conditional stimulus on this day. A 7000 cycles per second tone immediately preceding a had given no arousal. Record b taken after about 20 minutes in the harness with 26 conditional and unconditional stimulus pairings. Record c shows the first conditional stimulus presentation of the day.

By the sixth postoperative week, more than 400 pairings had been given. The EEG was now essentially normal and respiratory conditioned reflexes were at the 100 per cent level. Extensor rigidity seemed to preclude flexion conditioned reflexes so discrimination training was thus begun based on respiratory responses. This was excellent on the first day, i.e., conditioned reflexes and EEG arousal were usually absent to 7000 and 70 cycles per second tones while present to the 700 cycles per second conditional stimulus (Fig. 4). Training and testing for over 1000 trials showed the discrimination was made despite wide, random variations of the inten- 
sity of these tones. A similar, but not as consistent discrimination between 1300 and 700 cycles per second (Fig. 5) was established.

At the termination of the experiments, potentials of normal latency and form were recorded from cortical somatosensory areas I and II to stimulation of the sciatic nerve of the conditioned limb.

$$
\text { CAT } 11,6 \text { JULY } 56
$$
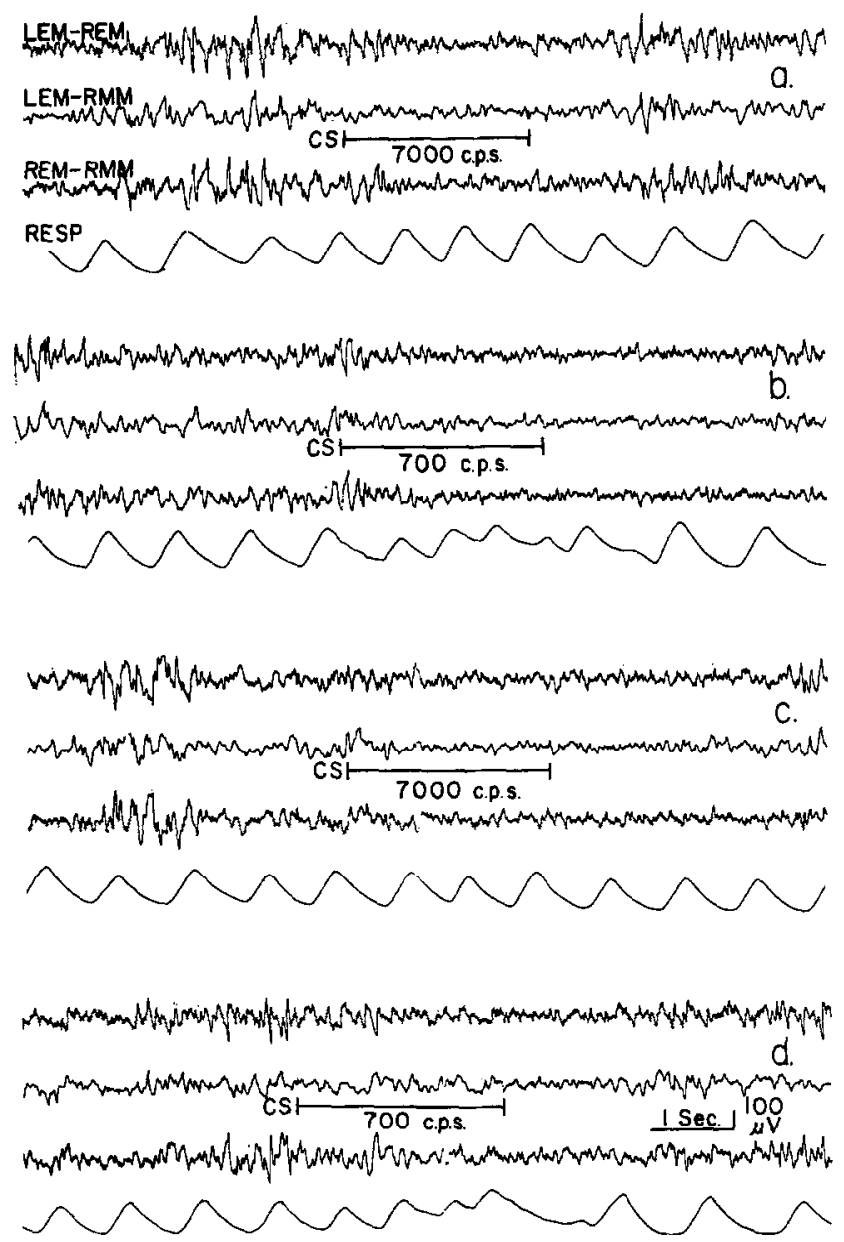

Fig. 4. Cat 11, forty-fourth postoperative day on which discrimination between tones was first examined. Records are consecutive. Note minimal EEG reaction though discrimination is excellent, i.e., pronounced respiratory conditioned reflexes to 700 but not to 7000 cycles per second. 


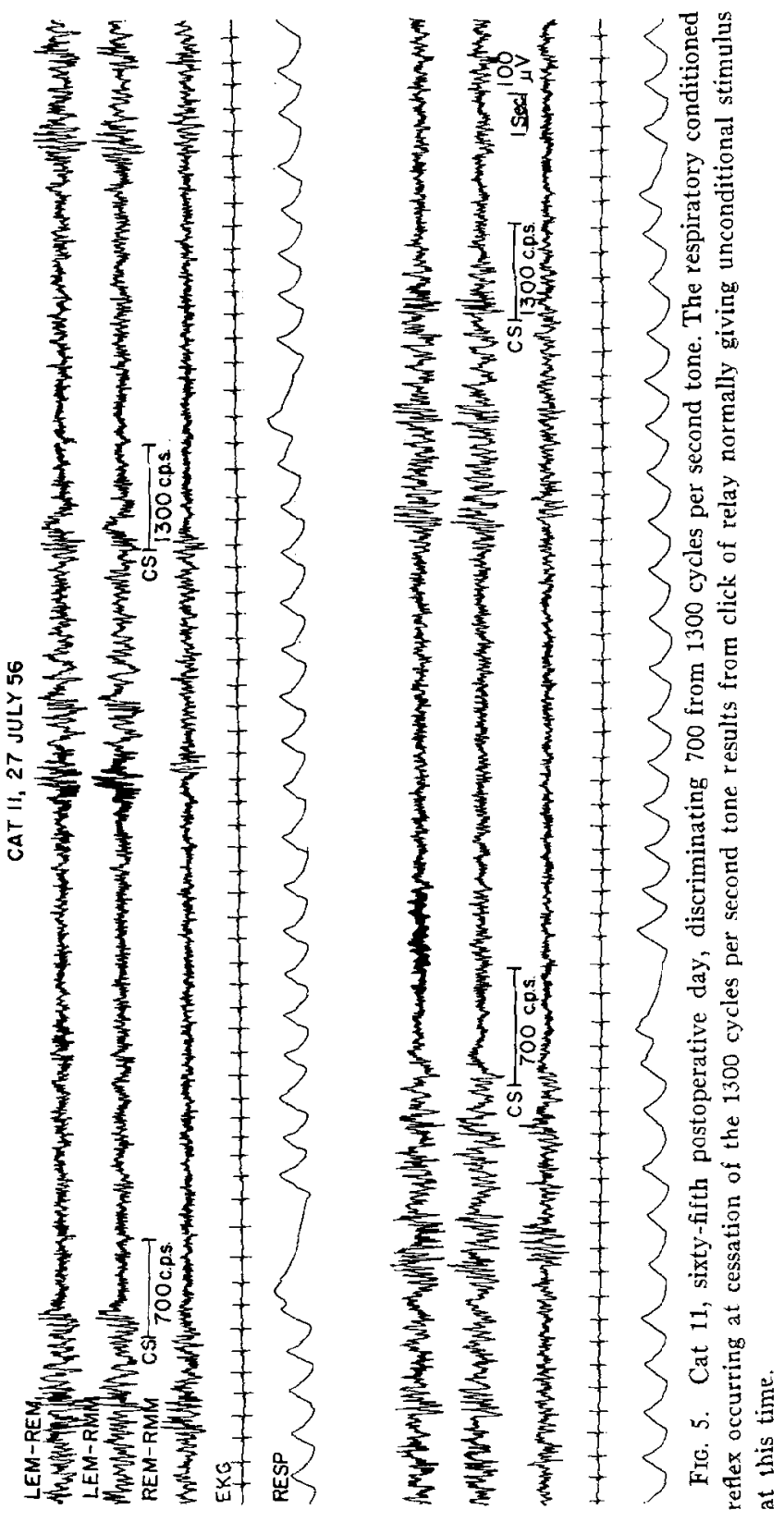


Cat 14. The lesion of $113 \mathrm{~mm}^{3}$ transected the mesencephalic reticular system and central brain stem (Figs. 6, 7). The red nucleus and the posterior commissure were totally destroyed and the right medial lemniscus was severed.
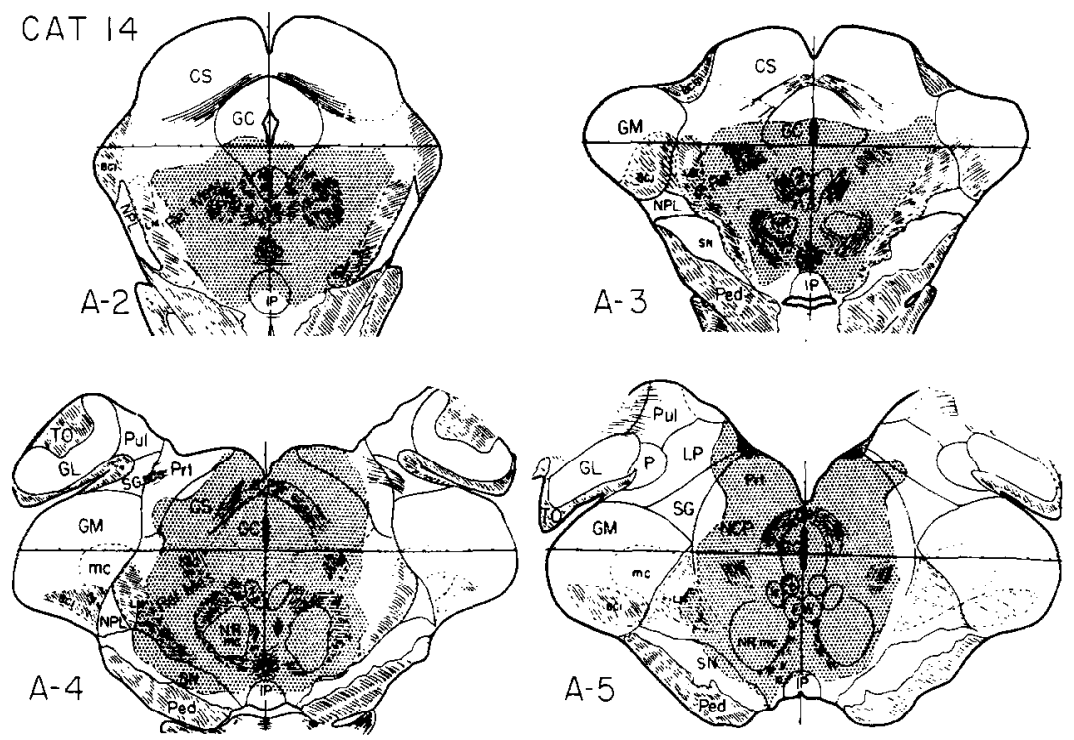

Fig. 6. Summary of lesions, cat 14.

The animal was observed for 21 days after surgery and, except for transient periods of struggling in the conditioning situation, remained in a cataleptic stupor for the entire period. Death occurred unexpectedly on the twenty-first postoperative day.

Prior to lesions, this cat received 550 trials using stimulation of marginal gyrus as conditional stimulus and gave no flexion responses and in a subsequent 150 trials to tonal conditional stimulus made only three flexions. Recording electrodes were then implanted. Respiratory conditioned reflexes were inconsistent. It was common in this animal, both before and after surgery, for extreme high voltage, slow action to occur in the EEG in a burst, following the conditional stimulus (Figs. 8 and 9). Even when this did not occur the preoperative EEG lapsed often into slower patterns between conditional stimulus presentations, which is not the usual case with restrained cats receiving shocks. During 21 trials of extinction given before placement of lesions, the period of arousal follow- 
ing each conditioned reflex shortened progressively, but no high voltage, slow activity was seen at this time either during or immediately following the conditional stimulus.

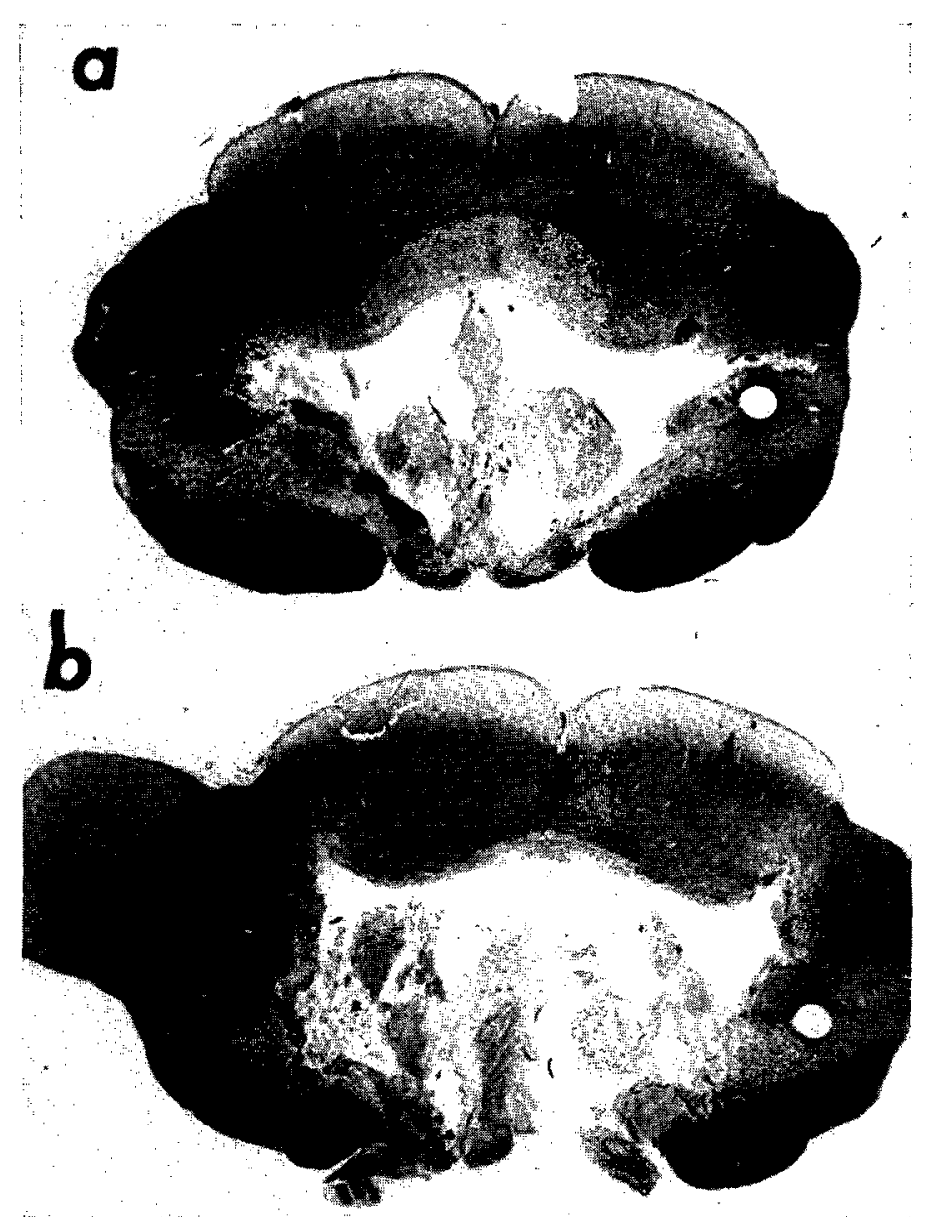

FIG. 7. Histologic sections through brain stem of cat 14, Weil stain.

On the first 4 postoperative days, EEG arousal patterns could not be obtained even to the unconditional stimulus. Auditory evoked potentials were present (e.g., Fig. 8). On the sixth postoperative day, the conditional stimulus alone could produce both a transition to lower voltage, faster 
patterns, and respiratory conditioned reflexes (Fig. 8). These conditioned reflexes disappeared after about 10 trials of further training on this day but were seen in subsequent sessions.

On the seventh postoperative day a peculiar seizurelike activity was
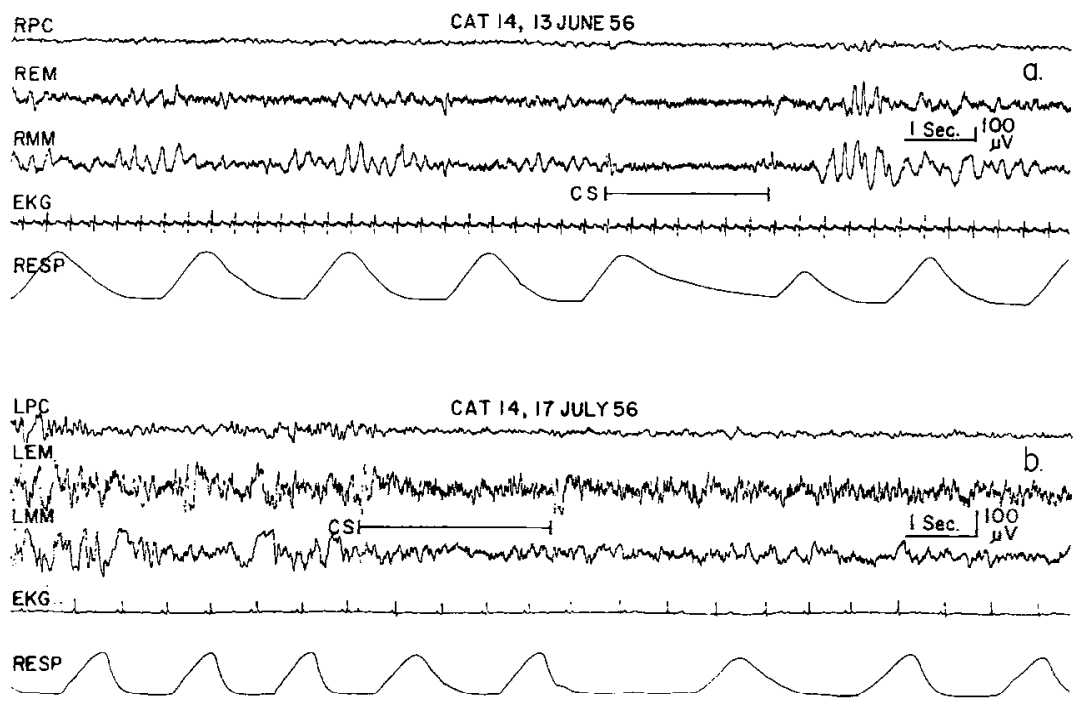

FIg. 8. Records from cat 14: a, prior to lesions, showing the ninth consecutive trial of a day without reinfcrcement with unconditional stimulus; $b$, the first conditional stimulus presentation on the sixth postoperative day. Note that the gain for record $b$ is double that of a so that the level of low voltage, fast action for the two records is roughly comparable.

noted. It seemed to originate in the posterior marginal gyrus lead and consisted of $200 \mu \mathrm{v}$ waves of $0.3 \mathrm{sec}$ duration which were followed by a burst of four to six spikes of $100 \mu \mathrm{v}$ amplitude and frequency of 12 per second. This grouping repeated about 1 per second for 10 to $35 \mathrm{sec}$. A shout or a conditional stimulus could halt such activity and either stimulus produced a respiratory alteration.

By the tenth day the "seizure" patterns were gone, but 1-sec bursts of 3 per second, $250 \mu \mathrm{v}$ activity were prominent in the posterior marginal gyrus. These slow patterns persisted even on the sixteenth and eighteenth days, but there were also long runs of low voltage, fast activity; respiratory conditioned reflexes became fairly common and slight flexion, struggling or head turning were noted to the conditional stimulus. On the 
cightecnth day, feeble, but discrete flexions were seen to the conditional stimulus on 6 of the 45 presentations. Low voltage, fast action prevailed at these times. However, even the unconditional stimulus failed to give low voltage, fast action between the twenty-fifth and thirty-second pairings on this day.

Cat 16. The lesion occupied $79 \mathrm{~mm}^{3}$ destroying major portions of the
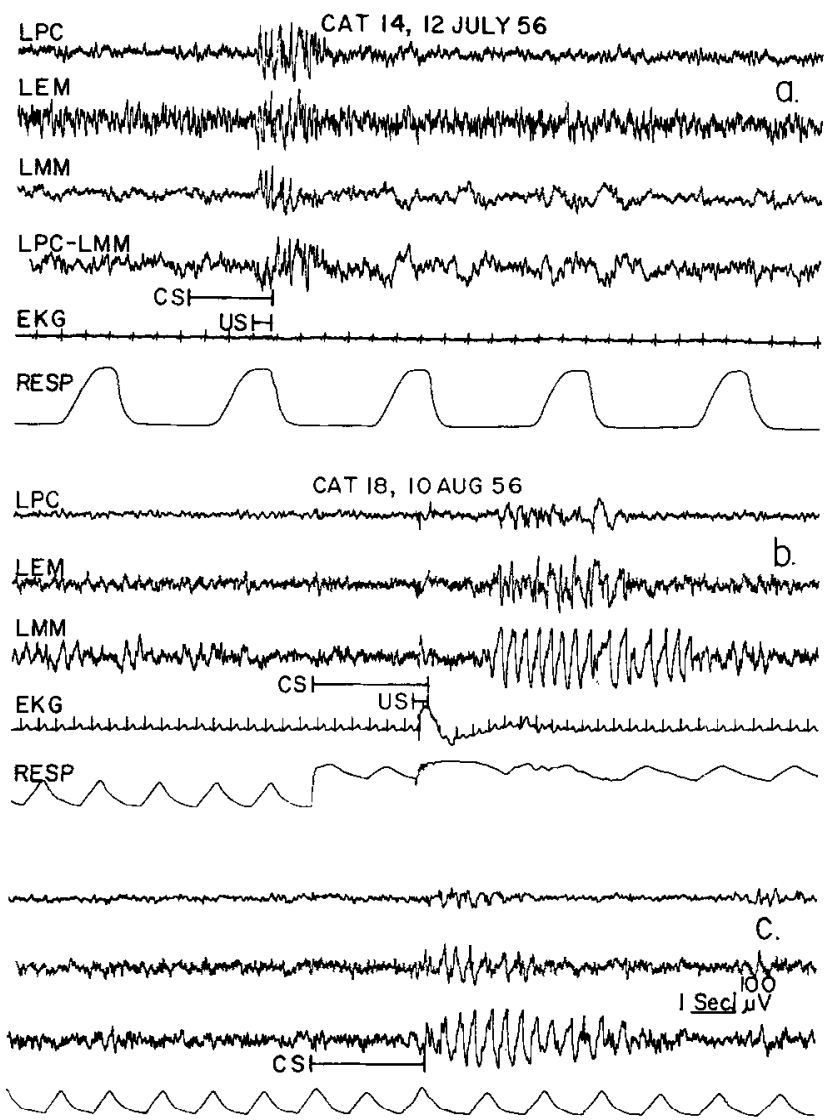

FIG. 9. Examples of high voltage, slow action following conditional stimulus with or without unconditional stimulus or conditioned reflexes: a, cat 14, second trial, 28 hours after lesion placement; $b$ and $c$, cat 18 , thirteenth postoperative day, trials 45 and 50. 
central mesencephalon (Fig. 10). ${ }^{3}$ Most of the red nucleus was intact, though probably "deafferented." The corpus callosum and fornix had been severed for 2 to $3 \mathrm{~mm}$ posteriorly.
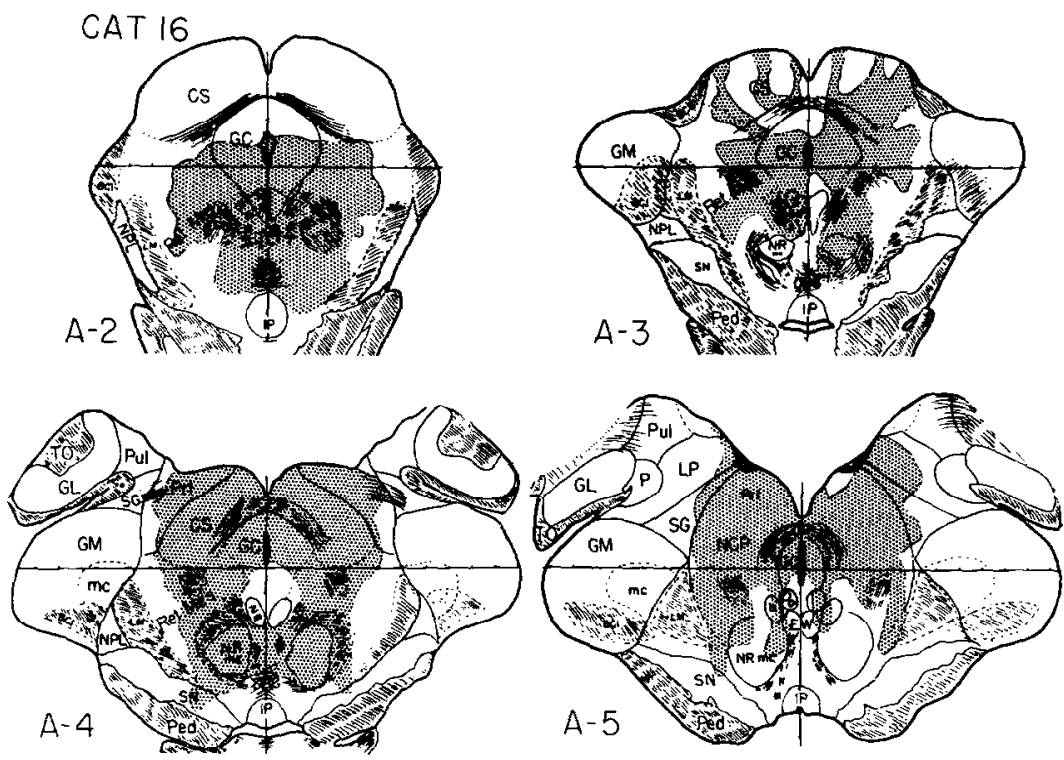

Fic. 10. Summary of lesion, cat 16.

This animal had less deficit than cats 11,15 , or even 18 . While behavior was certainly lethargic, catalepsy was minimal. The deficit was more one of posture and coordination. The limbs were so rigid that only a few steps could be taken without falling. Responsiveness to tactile stimulation, prior to sacrifice on the fourteenth postoperative day, seemed to wax and wane; at one moment no reaction other than spinal reflex withdrawal could be clicited to pinching of the rear legs, while a few seconds later the animal would whirl around upon the slightest touch. The head turned to the source of sounds, but visual tracking and blink reflexes to threat were absent. Cortical potentials evoked by sciatic, click, or photic stimuli appeared normal.

Using bulbocapnine restraint (3), this animal received 600 pairings of conditional and unconditional stimuli prior to surgery and gave flexion conditioned responses of up to $5 \mathrm{~cm}$ excursion 100 per cent of the time.

3 Photomicrographs appear in Fig. 3, p. 568, Ref. 5. 
On the second postoperative day, the EEG showed many runs of $300 \mu \mathrm{v}$, 6 per second activity. Short bursts of low voltage, fast action were also seen though without relation to stimulation; in fact, the unconditional stimulus sometimes triggered runs of high voltage, slow activity. Flexion conditioned reflexes were absent, but a few respiratory conditioned reflexes were observed and were accompanied by rapid, low amplitude activity superimposed on slower waves. On the ninth postoperative day after a total of 150 retraining trials (given in three sessions), flexion conditioned reflexes reappeared and occurred over 80 per cent of the time. Slow activity was now less prominent in the EEG (e. g., Fig. 11, for the eleventh postoperative day).

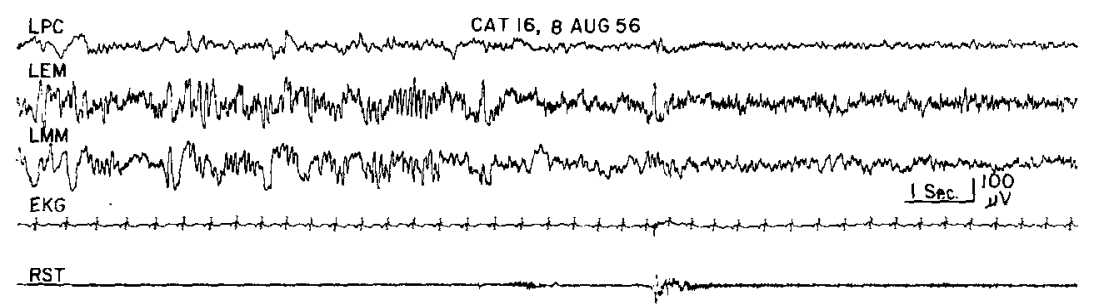

$\underline{\mathrm{CS}}$

us

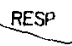

(

FIs. 11. Cat 16, eleventh postoperative day, showing EMG of a 1 to $2 \mathrm{~cm}$ flexion conditioned reflex.

By the thirteenth day the low voltage, fast activity was maintained continuously and was of essentially normal amplitude (i.e., lower than in Fig. 11, LEM and LMM). Startle responses but no conditioned responses were given to abrupt auditory stimuli, $4 \mathrm{~cm}$ flexion conditioned reflexes to the conditional stimulus. Extinction was then begun. On the twentysecond presentation, the flexion conditioned reflex was absent for the first time, though a respiratory conditioned reflex was still present. Forty minutes later, between the seventieth and eightieth presentations, flexion conditioned reflexes were absent and only three respiratory conditioned reflexes occurred. There were no slow waves in the EEG during these 10 trials, and the potential evoked in middle ectosylvian gyrus (Fig. 11) was not altered in amplitude. Only one pairing of conditional and unconditional stimuli was necessary to restore the flexion conditioned reflexes. 


\section{Lesions of Medial Diencephalon}

Cat 9. The lesion, as shown in Fig. 12, destroyed most of the posterior hypothalamus and transected the diencephalon in the saggital plane for about $2.5 \mathrm{~mm}$. The greater part of the mamillothalamic tract, median forebrain bundle, and dorsal medial, central medial, ventral medial, and
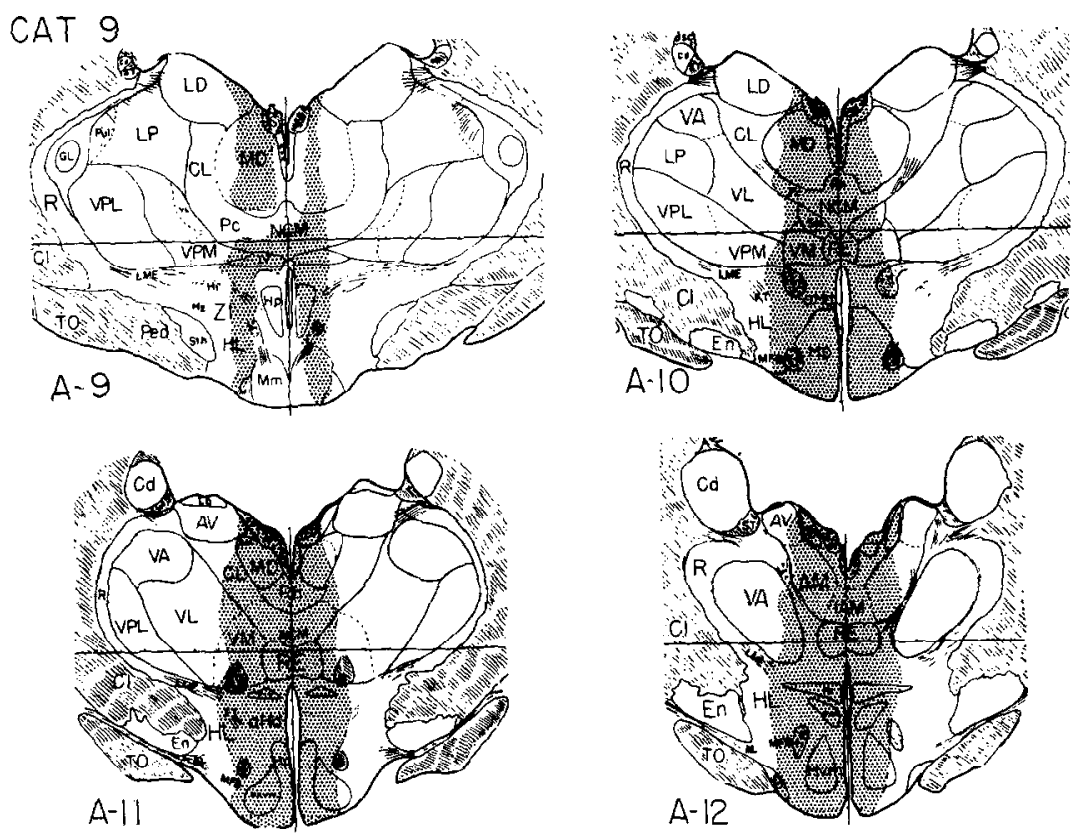

FIG. 12. Summary of lesion, cat 9.

reuniens nuclei were destroyed. The mamillary bodies and zona incerta received relatively minor damage. The lesion totaled $83 \mathrm{~mm}^{3}$

The animal was comatose for 30 hours following surgery, but by the end of the second day could stand and walk a few steps. Until the end of the experiment on the eighth postoperative day, it was lethargic when undisturbed, but became extremely hyperactive when fed or lifted.

Data on the preoperative training of this cat have already been given (4). It maintained a 100 per cent level of flexion conditioned reflexes for several days during about 200 trials of "overtraining." In the first postoperative test carried out on the second day after surgery, this animal made an unequivocal flexion conditioned reflex with an EEG arousal re- 
action to the first presentation of the conditional stimulus. These responses continued to occur to every conditional stimulus and were not evoked by nonspecific auditory stimuli (Fig. 13). Fifty presentations of the condi-
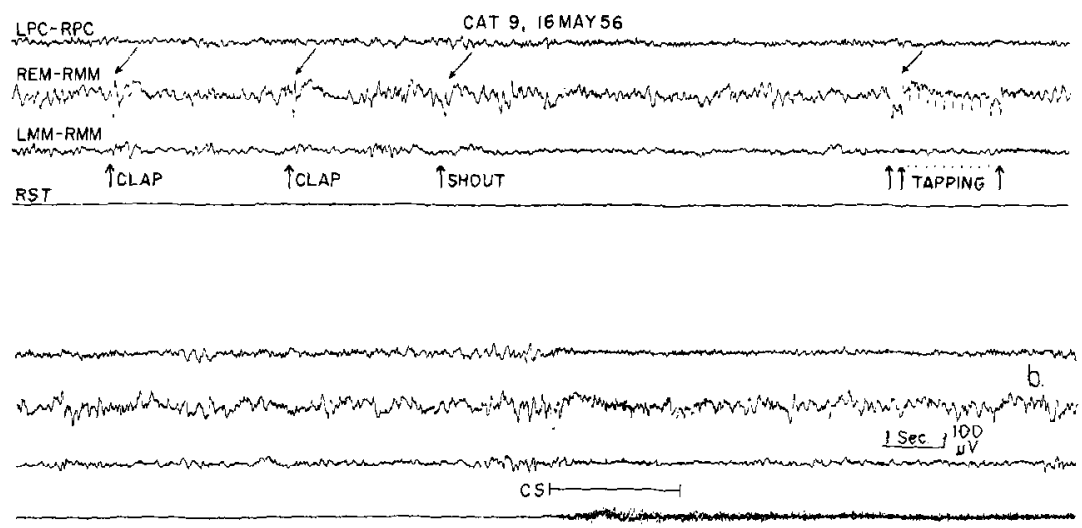

FIG. 13. Second postoperative day, cat 9. Potentials are evoked in auditory cortex and low voltage, fast activity appears to nonspecific auditory stimulation, but conditioned reflexes as shown in EMG record b, occur only to the tonal conditional stimulus.

tional stimulus were then given on this same day unreinforced by the unconditional stimulus. During this procedure, the magnitude of the conditioned reflex roughly approximated the degree of electrocortical arousal to the conditional stimulus. High voltage, slow activity prevailed for most of the period between the fortieth and fiftieth presentations and the two minimal flexion responses which occurred here werc accompanied by only transitory low voltage, fast action. Administration of unconditional stimulus with the conditional stimulus immediately restored the conditioned reflexes and EEG responses to their previous levels.

Cat 15. The lesion occupied about $101 \mathrm{~mm}^{3}$ It destroyed the mamillary bodies, and essentially all of center median, field $\mathrm{H}_{1}$ of Forel, and the habenulopeduncular tract (Fig. 14) ${ }^{4}$ The posterior hypothalamus and zona incerta received major damage. The posterior commissure and interpeduncular nucleus were untouched. The fornix and corpus callosum were severed for about $4 \mathrm{~mm}$.

The first 2 postoperative weeks saw a gradual recovery from profound

4 Photomicrographs appear as Fig. 4, p. 587 in Ref, 5 and Fig. 149, Ref. 6. 
cataleptic stupor and in this the animal was very similar in appearance and behavior to cat 11 . Violent struggling occurred to noxious stimuli, but left alone, the animal was immobile. Spontaneous walking, however, returned by the third week. In the fifth week, tactile placing of the rear legs was excellent and general responses were given to light touch of the
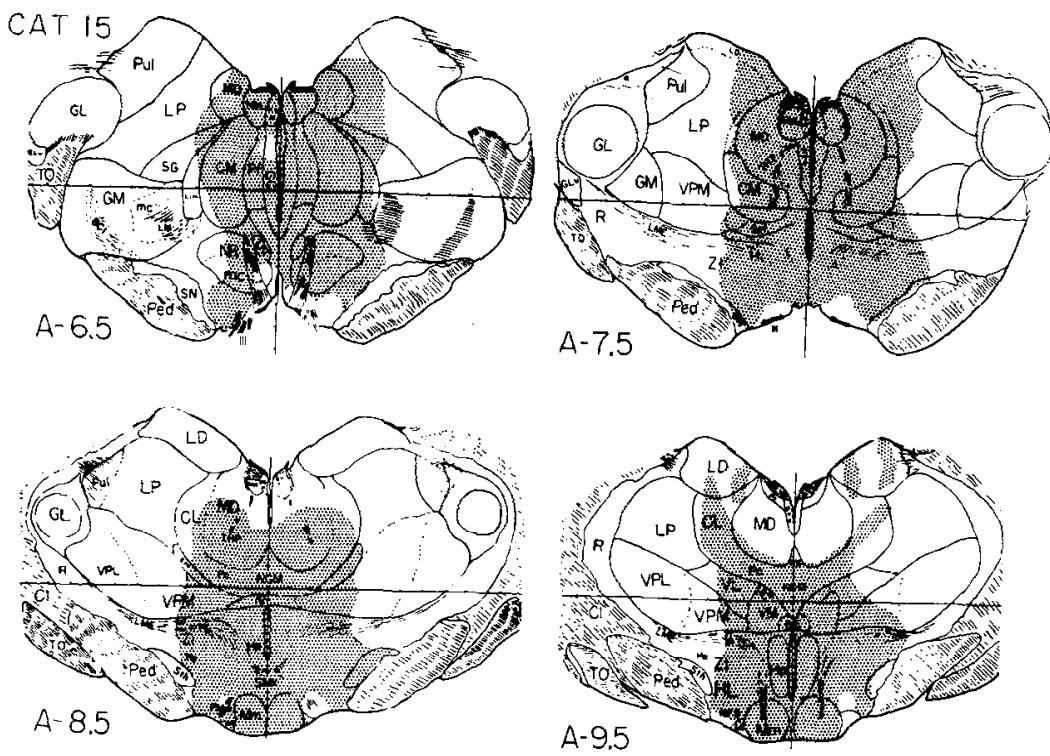

Fig. 14. Summary of lesion, cat 15.

rear legs or to auditory stimuli, e.g., the cat would turn around when a food pan was scraped behind her. Blinking to sudden approach of an object was very easily elicited and was not the result of associated noise or air movement. The animal walked in a slow, deliberate manner with head down, and still displayed cataleptic posturing. It was killed after 38 days.

Preoperatively, a criterion of 8 flexion conditioned reflexes in 10 presentations of the conditional stimulus was obtained in 250 trials and respiratory conditioned reflexes occurred 95 per cent of the time. No conditioned reflex of any kind (save the blink to threat as noted above) was recorded during 1325 postoperative trials in 26 training sessions over 37 days.

During the first 2 to 3 weeks, 4 to 10 per second activity predominated 
with occasional 3 to 4 per second bursts. The unconditional stimulus during this period produced violent struggling, and $100 \mu \mathrm{v}$ waves in marginal gyrus sometimes endured through this behavior. However, comparison of the EEG records showed that the electrocortical activity in this cat was less disturbed than in 4 other animals that readily gave conditioned reflexes postoperatively. By the third week, a nearly normal EEG was present. The persistence of low voltage, fast activity throughout each training session thereafter precluded study of arousal reactions to the conditional and unconditional stimuli. On rare occasions, they occurred to the unconditional stimulus but only equivocally to the conditional stimulus (Fig. 15). Potentials evoked to photic, auditory, and sciatic stimulation at the end of the experiment were normal.

Cat 18. The lesion of $47 \mathrm{~mm}^{3}$ was the smallest of this series of animals. The only nuclear groups approaching near total destruction were center median and the dorsal medial nucleus (Fig. 16). The red nucleus was un-
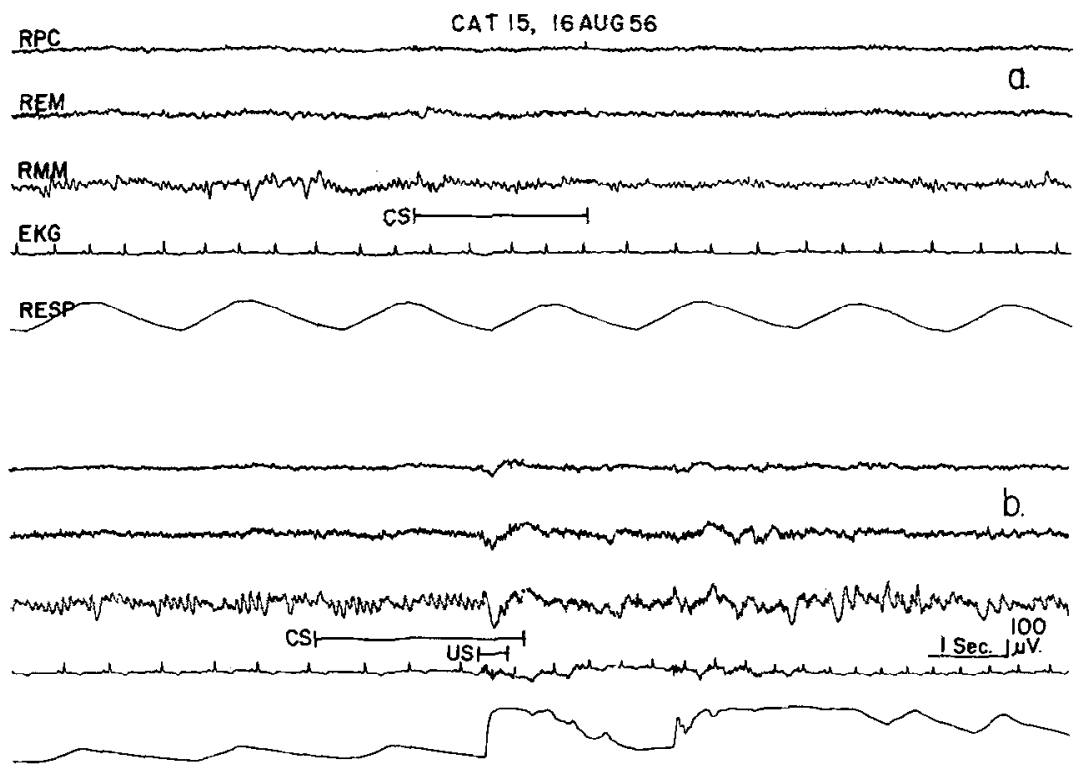

FIG. 15. Cat 15, thirty-sixth postoperative day: a, following the twenty-sixth pairing of the day bringing the total to 1253 postoperative pairings of conditional and unconditional stimuli; $b$, the forty-eighth pairing of the same day showing transition to low voltage, fast activity in marginal gyrus to unconditional stimulus but not to conditional stimulus. 
touched. There was unilateral damage to the mamillary bodies. The zona incerta and field $\mathrm{H}_{1}$ of Forel were heavily damaged, but escaped posteriorly. The corpus callosum and fornix were divided for several millimeters.

As with cats 11 and 15, a profound cataleptic stupor prevailed through-
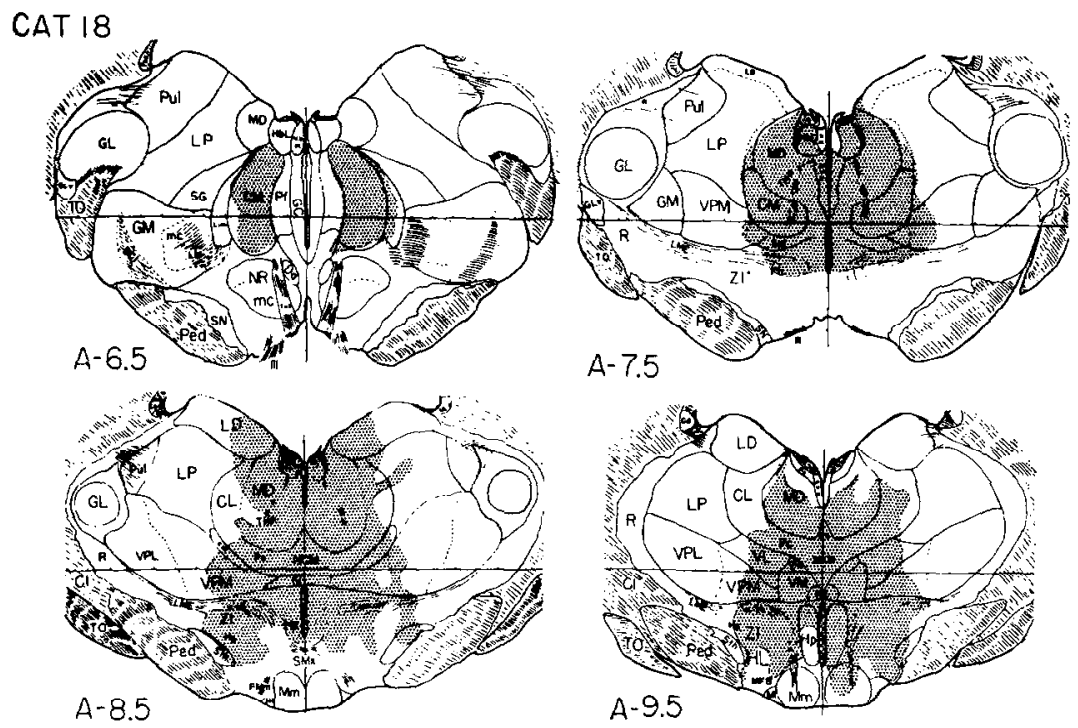

FIG. 16. Summary of lesion, cat 18.

out the first postoperative week. This condition gradually abated, but the animal was still very lethargic and would remain in odd postures for lengthy periods when tested prior to sacrifice on the twenty-ninth day. On the twenty-sixth day when conditioned reflexes had returned, it could stand and walk slowly, ate spontaneously and reacted promptly by turning to the appropriate side when hairs were lightly touched on either hind leg. There was no tactile placing, however. Visual tracking of a moving object was excellent and clumsy attempts were made to strike such objects with the forepaw. The animal reacted to the experimenter's approach by "chirping" and to the conditioning apparatus by spitting and struggling when lifted towards it.

The animal received 600 trials, mostly under bulbocapnine restraint, prior to surgery, and attained a 100 per cent level of flexion and respiratory conditioned reflexes for the last 100 trials.

During the first few days following surgery, the unconditional stimulus 
did not alter the high voltage, slow background in the EEG. By the ninth postoperative day (third retraining session), the unconditional stimulus gave 1 to $5 \mathrm{sec}$ of low voltage, fast activity, and by the thirteenth day, a more nearly normal level of electrical activity had returned (Fig. 9). At this time and for the next week or so, the combination of conditional and unconditional stimuli alone very frequently precipitated high voltage, slow bursts (Fig. 9). Respiratory conditioned reflexes were seen sporadically (Fig. 9), but hind leg conditioned reflexes were absent. Training was intensified so that two sessions per day were given, sometimes using 75 trials per session. Respiratory conditioned reflexes became increasingly common. Hind leg conditioned reflexes appeared on the twenty-fourth day following a total of 800 retraining trials. By the twenty-sixth day, the hind leg conditioned reflexes, which consisted of a stiff, forward thrust of the right hind leg, occurred nearly 100 per cent of the time and electrical activity was essentially normal. Tones of 500 or 2000 cycles per second did not give conditioned reflexes whereas 700 or 1000 cycles per second did.

\section{Medial Lemniscus}

Several attempts were made surgically to sever the lemniscal systems at the collicular level. Only cat 21 deserves mention and even this case is rendered equivocal by survival of a small mesoventral portion of the medial lemniscus on the left (Fig. 17a), probably carrying sensation from the right face and neck but possibly carrying a few fibers from the conditioned right forelimb. The lateral lemniscus was probably intact, though fibers coursing from the nucleus of the lateral lemniscus direct to medial geniculate body should have been severed if they run ventrally in the inferior colliculus. The picture of fibers from the intercollicular commissure taking up a lateral position in the brachium of the inferior colliculus, as noted by Woollard and Harpman (24) was extraordinarily clear (Fig. 17c).

After 9 months, tactile placing was present in all limbs. Objects were avoided expertly in walking or jumping down, and pinching the tail or toes evoked strong affective reactions but no sign of effective localization of the source of stimulation. The EEG was normal from the third postoperative day. By the tenth day, respiratory conditioned reflexes were present in 7 of 23 trials, but flexion conditioned reflexes were absent although they had been at the 100 per cent level for the last 100 of 600 preoperative training trials. Considerable retraining was necessary (begun 


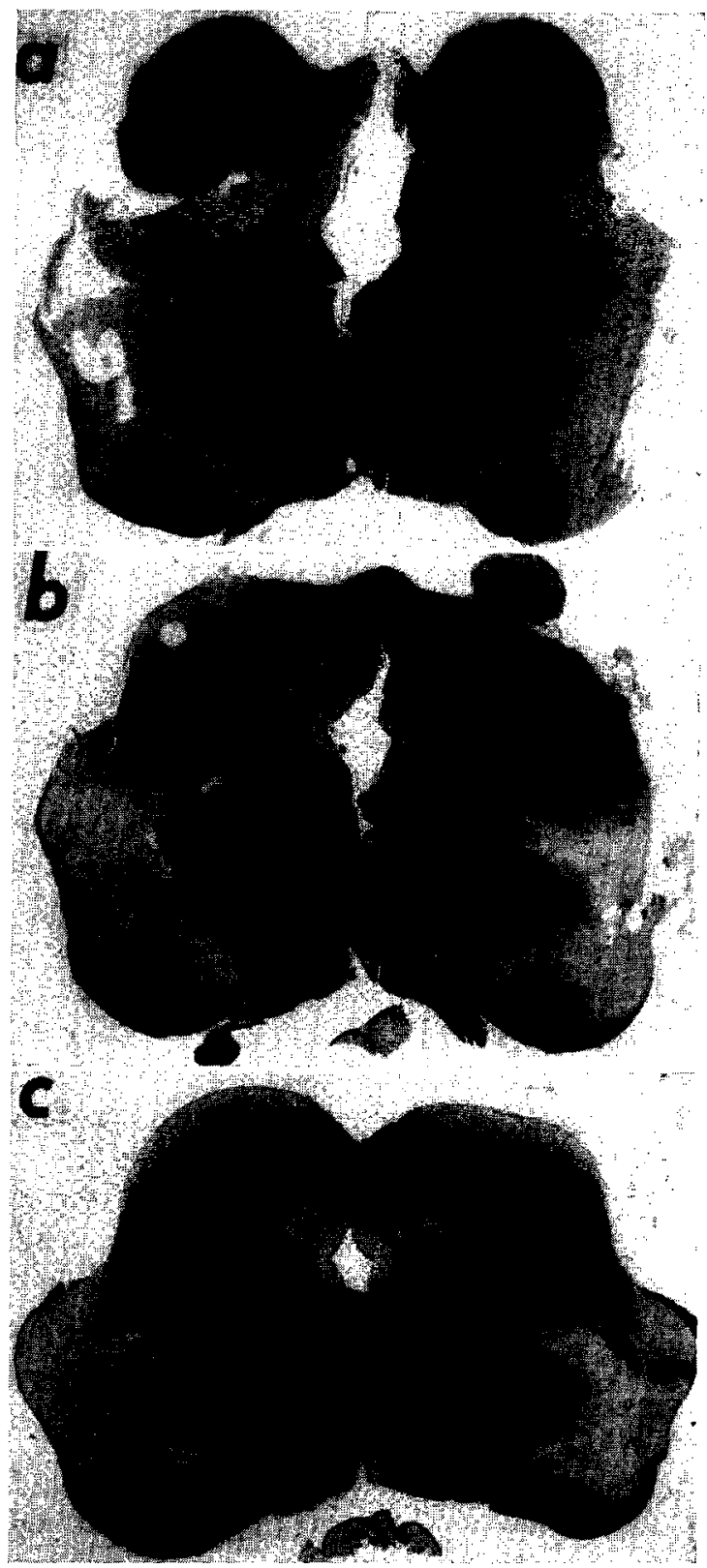

FIG. 17. Histologic sections through brain stem of cat 21, Weil stain. 
following negative tests given after 1 month and 6 months recovery) to re-establish flexion conditioned reflexes. A high level of flexion conditioned reflexes, however, was regained and discrimination between the 700 cycle reinforced tone and a 70 cycle nonreinforced one was essentially perfect regardless of intensities.

\section{Discussion}

It is apparent that defensive conditioned reflexes can be obtained following drastic, debilitating lesions of the medial brain-stem systems. The conditioned reflexes were retained from one day to the next and discrimination of a reinforced from a nonreinforced conditional stimulus was excellent. Thus, the performance of a learned act by these animals greatly exceeded the capabilities of the preparations described by Bard and Macht (2) in which the brain stem was totally transected at the mesencephalic level. The more extensive studies on brain-stem lesions and behavior, undertaken by Stellar and his colleagues $(21,23)$, seem to be yielding data in essential agreement with that reported here. Survival of defensive conditioned reflexes after near total destruction of the mesencephalic reticular system stands in striking contrast to the abolition of conditioned salivary responses reported by Hernandez-Peon and his colleagues (11) to follow relatively minor lesions in this region. Such contradiction, however, may reflect only the great differences in response to food versus shock.

The observations on general behavior and EEG abnormalities were all concordant with those of others $(13,15,16)$, save that the return of low voltagc, fast patterns was perhaps somewhat earlier and certainly more complete with greater survival times. As noted by Genovesi and co-workers (9), very large lesions were necessary to produce persistent high voltage, slow patterns and even in such cases the effect was not a permanent one (compare cat 16 with 14 and 15).

The significance of the correlation of EEG arousal reactions with conditioning remains problematical. As a general rule, conditioned reflexes were either not made in the absence of low voltage, fast patterns or were much more complete and unequivocal when low voltage, fast action was present. There were, however, as noted previously in other circumstances (4), important exceptions when unquestionable conditioned reflexes were observed with no trace of an arousal reaction in the areas sampled (e.g., Fig. $2 \mathrm{~b}$ and $\mathrm{c}$ ). Discrimination between tones could also occur without any obvious alteration of moderately slow patterns (Fig. 4) confirming similar observations of Sharpless and Jasper (20) and Rowland (19). On 


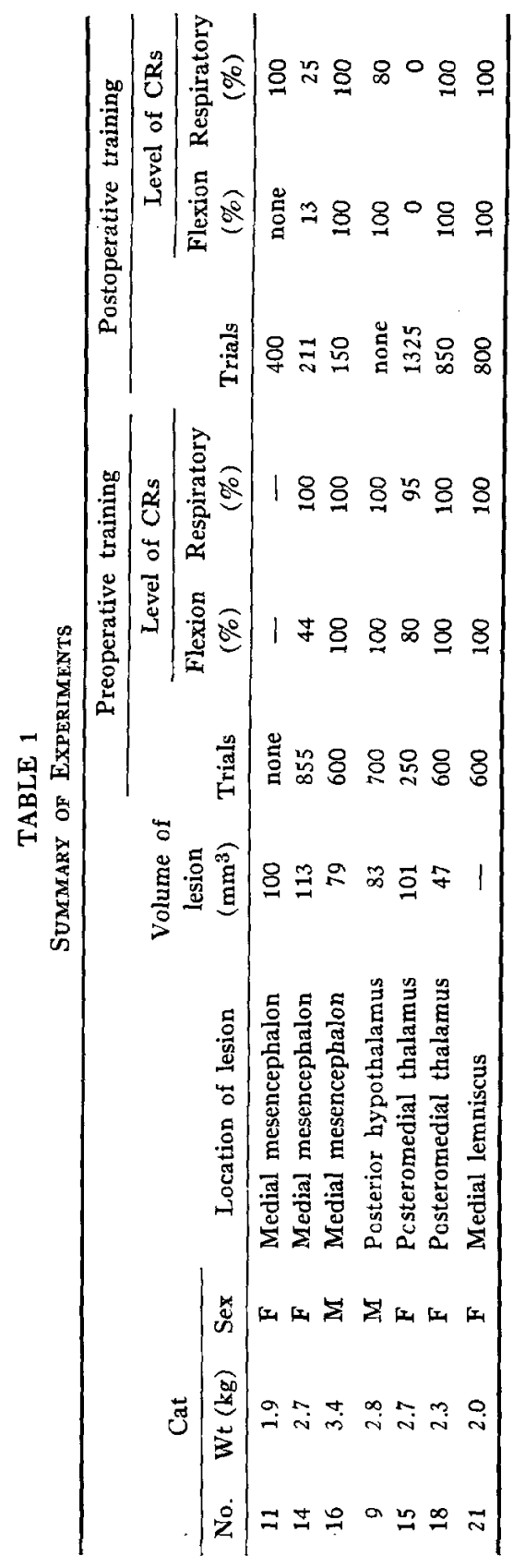


the other hand, even when observed in individuals prone to give high voltage, slow responses to a reinforced conditional stimulus, no high voltage, slow patterns developed in association with a conditional stimulus that was being used for extinction.

Destruction of the region which includes the center median, posterior hypothalamus, and mamillary bodies completely abolished conditioning in one animal (cat 15). Cats 11 and 14 had lesions in the mesencephalon comparable in size to cat 15 (Table 1), and had performed poorly or not at all preoperatively (whereas cat 15 had normal performance preoperatively), yet were much superior in postoperative conditioned performance. In general behavior, cat 15 was at least equal to cats 11 and 14 , and low voltage, fast action prevailed in the EEG for several weeks of postoperative training. The lemniscal systems were intact anatomically and electrophysiologically. Together, these facts suggest the region destroyed in cat 15 is far more important for the type of conditioning studied, than are the medial mesencephalic or anterior-medial thalamic and hypothalamic areas.

\section{References}

1. Amassian, V. E., and R. V. De Vito, Unit activity in reticular formation and nearby structures. J. Neurophysiol. 17: 575-603, 1954.

2. BARD, P., and M. B. MACHT, The behavior of chronically decerebrate cats. In "Ciba Foundation Symposium on the Neurological Basis of Behavior," G. E. W. Wolstenholme and C. M. O'Connor (Ed.). Boston, Little, Brown \& Co., 1958 (ref. pp. 55-75).

3. BeCK, E. C., and R. W. Dory, Conditioned flexion reflexes acquired during combined catalepsy and de-efferentation. J. Comp. Physiol. Psychol. 50: 211-216, 1957.

4. BECK, E. C., R. W. Doty, and K. A. Koor, Electrocortical reactions associated with conditioned flexion reflexes. Electroencephalography, Montreal 10: 279289, 1958.

5. Doty, R. W., General discussion, In "Henry Ford Hospital Symposium: Reticular Formation of the Brain," H. H. Jasper, L. D. Proctor, R. S. Knighton, W. C. Noshay, and R. T. Costello, (eds.). Boston, Little, Brown \& Co., 1958 (ref. pp. 582-588).

6. Doty, R. W., Brain stimulation and conditional reflexes. In "Central Nervous System and Behavior," M. A. B. Brazier (ed.). New York, Josiah Macy, Jr. Foundation, 1959 (ref. pp. 241-306).

7. Galambos, R., G. Sheatz, and V. G. Vernier, Electrophysiological correlates of a conditioned response in cats. Science 123: 376-377, 1956.

8. Gastaut, H., C. Jus, F. Morrell, W. Storm van Leeuwen, S. Dongier, R. Naquet, H. Regis, A. Roger, D. Bekkering, A. Kamp, et J. Werre, Etude topographique des réactions électroencéphalographiques conditionées chez l'homme. Electroencephalography, Montreal 9: 1-34, 1957. 
9. Genovesi, U., G. Moruzzi, M. Palestini, G. F. Rossi, and A. Zanchetti, EeG and behavioral patterns following lesions of the mesencephalic reticular formation in chronic cats with implanted electrodes. Abst. Comm. XXth Int. Physiol. Cong., p. 335, 1956.

10. Hernández-Peón, R., M. Jouvet, and H. Scherrer, Auditory potentials at cochlear nucleus during acoustic habituation. Acta neur. latinoam. 3: 144156, 1957.

11. Hernández-Peón, R., H. Brust-Carmona, E. Eckhaus, E. López-Mendoza, and C. Alcocer-Cuaron, Effects of cortical and subcortical lesions on salivary conditioned response. Acta neur. latinoam. 4: 111-120, 1958.

12. Ingram, W. R., R. W. Barris, and S. W. Ranson, Catalepsy: an experimental study. Arch. Neur. Psychiat., Chi. 35: 1175-1197, 1936.

13. Ingram, W. R., J. R. Knott, M. D. Wheatley, and T. D. Summers, Physiological relationships between hypothalamus and cerebral cortex. Electroencephalography, Montreal 3: 37-58, 1951.

14. Jasper, H. H., and C. AJMone-Marsan, "A Stereotaxic Atlas of the Diencephalon of the Cat," 15 pp. + 52 plates. Ottawa, National Research Council of Canada, 1954.

15. Knott, J. R., W. R. Ingram, and W. D. Chiles, Effects of subcortical lesions on cortical electroencephalogram in cats. Arch. Neur. Psychiat., Chi. 73: 203215,1955 .

16. Lindslex, D., L. H. Schrtiner, W. B. Knowles, and H. W. Magoun, Behavioral and EEG changes following chronic brain stem lesions in the cat. Electroencephalography, Montreal 2: 483-498, 1950.

17. Lissak, K., Die Rolle der subkortikalen Mechanismen bei den bedingten Reflexen. Zschr. ärtz. Fortbild. 7/8, 338-342, 1956.

18. Penfield, W., and H. JAsper, "Epilepsy and the Functional Anatomy of the Human Brain." Boston, Little, Brown \& Co., 1954.

19. Rowland, V., Differential electroencephalographic response to conditioned auditory stimuli in arousal from sleep. Electroencephalography, Montreal 9: 585-594, 1957.

20. Sharpless, S., and H. JASPER, Habituation of the arousal reaction. Brain, Lond. 79: 655-680, 1956.

21. Sprague, J. M., W. W. Chambers, E. Stellar, C. N. Liu, and K. Robson, Chronic reticular and lemniscal lesions in cats. Fed. Proc., Balt. 17: 155, 1958.

22. Starzi, T. E., C. W. Taylor, and H. W. Magoun, Collateral afferent excitation of reticular formation of brain stem. J. Neurophysiol. 14: 479-496, 1951.

23. Strelar, E., W. W. Chambers, C. N. Liu, M. Levitt, and J. M. Spracue, Behavior of cats with chronic reticular and lemniscal lesions. Fed. Proc., Balt. 17: 156.

24. Woollard, H. H., and J. A. Harpman, The connexions of the inferior colliculus and of the dorsal nucleus of the lateral lemniscus. J. Anat., Lond. 74: 441$458,1940$.

25. Yoshir, N., P. Pruvot, and H. Gastaut, Electrographic activity of the mesencephalic reticular formation during conditioning in the cat. Electroencephalography, Montreal 9: 595-608, 1957. 